\title{
SAND AS A SOIL STABILIZER
}

\author{
Kollaros G. ${ }^{1}$ and Athanasopoulou A. ${ }^{1}$ \\ ${ }^{1}$ Democritus University of Thrace, Department of Civil Engineers, 67130, Xanthi, Greece, \\ gkoll@civil.duth.gr,anatha@civil.duth.g
}

\begin{abstract}
Clayey soils often exhibit undesirable engineering behaviour such as low strength, swelling and shrinkage characteristics etc. To improve these properties, the common method followed is stabilization. An experimental program carried out in this study aims to highlight the physical mechanisms of stabilization of an expansive soil by adding an inert material (sand). The study aimed to analyze the effect of stabilization on the variation of soil consistency and the results have shown that soil consistency improved appreciably. The findings of the laboratory testing procedures also presented substantial improvement in strength with the addition of sand percentages up to $60 \%$ by weight of soil, as well a noticeable alteration in the moisture-density relation. The soil tested could be used as subgrade material in pavement structures for low volume bearing roads, after its stabilization with fine sand. A further step in the investigation process could be the analysis of the swelling potential of clayey soils in conjunction with the addition of other waste materials along with sand, as well as the cost-benefit relationships of stabilization with sand in large projects like the highway construction.
\end{abstract}

Keywords: clay, additive material, engineering characteristics, physical properties, stabilization.

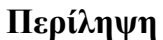

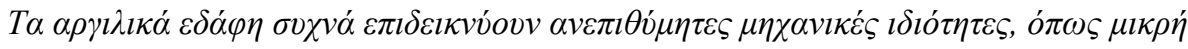

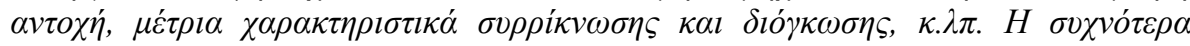

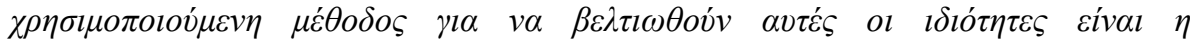

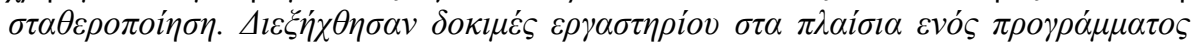

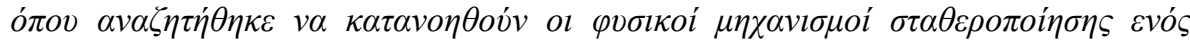

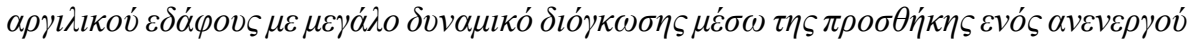

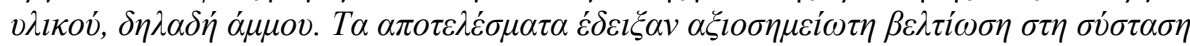

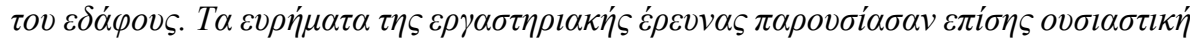

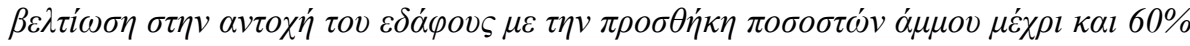

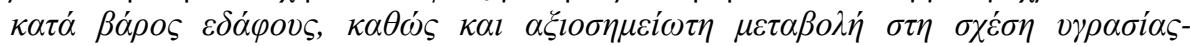

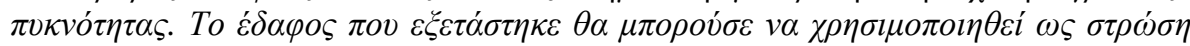

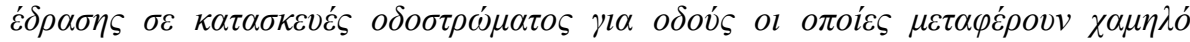

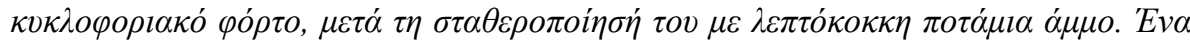

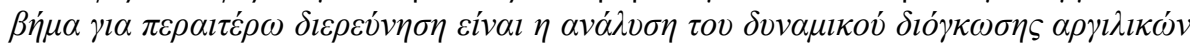

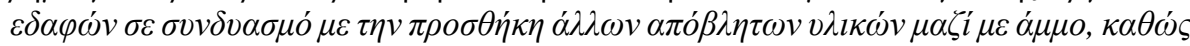

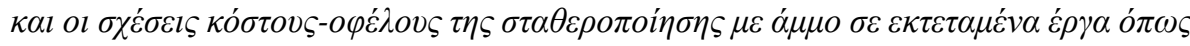

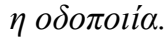

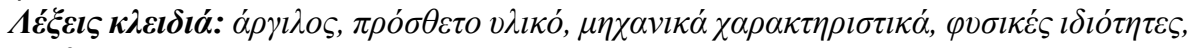
$\sigma \tau \alpha \theta \varepsilon \rho о \pi о i ́ \eta \sigma \eta$. 


\section{Introduction}

Subgrade plays an important role in safe and cost effective pavement construction, given that the materials are suitable. Usually, there is a requirement for the improvement of both the plasticity and the bearing capacity of local soils. The stabilization methods are a common suggestion for such goals to be achieved. There are many techniques for soil stabilization and the choice between them depends on several economic, practical and environmental parameters. Discrete techniques are chemical stabilization, thermal stabilization, stabilization by additives such as lime and cement.

Sand is a naturally occurring granular material. Because of its high load bearing capacity in confined condition, sand could be used as a filler material. So, sand could be used in varying proportions as admixture to cohesive soils altering the properties of plasticity, compaction and strength of the mixtures (Khemissa et al., 2015; Louafi et al., 2012). This work aimed to evaluate the laboratory results obtained when a black clay soil was tested for the dry density-moisture relationship and for the unconfined compressive strength after the admixture of sand in different proportions.

Soils showing volumetric changes when they respond to changes in their moisture content are characterized as expansive. Such soils exhibit swelling shrinkage and often result to damage on civil engineering constructions like the transportation infrastructure. The change in soil volume is highly dependent on both the mineralogy of materials composing the soils and their proportions in the soil mass. Problems in technical structures have arisen in various places in Greece; examples of such problematic projects are the National Road near Thebes, Central Greece, along a $20 \mathrm{~km}$ section (Gkasios et al., 2000), and the provincial road network of N. Evros prefecture (Papakyriakopoulos et al., 2006), where geotechnical problems have been noted.

Numerous researchers have applied inert materials to soils, as a method of stabilizing them (Bengraa et al., 2005; Kaoua et al., 1994; Lamara et al., 2005; Louafi et al., 2011). Though the research works have shown that the addition of inert materials is a promising technique for stabilizing such soils, there are still many open questions on the behaviour of an amended soil that require answers from the engineers' community. In this work, the effect the addition of sand on the characteristics of a clayey soil is being studied.

In a research work (Chavali et al., 2014) it was found that the maximum dry density of clay-sand mix improved with the addition of sand up to $30 \%$; thereafter it decreased. In the same report, the optimum moisture content decreased up to $30 \%$ sand content thereafter it increased slightly.

There is an interest in investigating the simultaneous action of sand and other materials in stabilization trials (Bhatta, 2008). Sharma et al. (2012) worked on use of sand, rice husk ash and waste plastic fiber for improving compaction characteristics of clayey soil for use as subgrade material. The influence of materials such as fly ash or river sand on compaction, and strength characteristics of black cotton soil has been extensively investigated in countries like India (Ameta et al., 2007; Sharma et al., 2013; Singh et al., 2014) or Nigeria (Madu, 1975) where problems are encountered due to cyclic swelling and shrinking behaviour of the soils. In practice, construction plans in which sand is used as a stabiliser instead of cement or lime could lead to minimised construction costs for roads carrying medium density traffic.

A research work in Uganda (Jjuuko et al., 2011) showed that maximum dry density (MDD) and optimum moisture content (OMC) increased from 1867 to $2357 \mathrm{~kg} / \mathrm{m}^{3}$ and decreased from 16.5 to $8.5 \%$, respectively, at sand blends of $20-100 \%$ while the unconfined compressive strength decreased from 787 to $95 \mathrm{kPa}$ at sand blends of $20-60 \%$.

According to stabilization techniques followed in order to improve the soil, the finer soil particles are replaced with coarser particles of sand admixture. In such a way, a uniform gradation of particles in the soil is created and the composite mix formed possesses both cohesion and friction. Furthermore, when properly mixed, placed and compacted at site, the soil exhibits improved load carrying capacity. 
Subgrade plays an important role in safe and cost effective pavement construction, given that the materials are suitable. Usually, there is a requirement for improvement of both the plasticity and the bearing capacity of local soils. Stabilization is a common solution for such goals to be achieved. Sand is a naturally occurring granular material. Due to its high load bearing capacity in confined condition, it could be used as a filler material. Sand could be used as admixture to cohesive soils altering the properties of plasticity, compaction and strength of the mixtures (Roy, 2013).

\section{Materials and Methods}

The soil samples for the laboratory investigation were collected at a location where the thickness of swelling soils varies from a few meters to several tens of meters, appearing in 1 to 3 meters superimposed layers which are alternating with sand, gravel or cobble layers. The clay content, as well as the mechanical behaviour, of these soils also varies greatly from site to site. The clay sampled had a dark greyish colour. The grain size distribution of the selected clayey soil has been determined by both the dry method (AASHTO T27-11) and hydrometer analysis. The grain size distribution of the soil is shown in Figure 1.

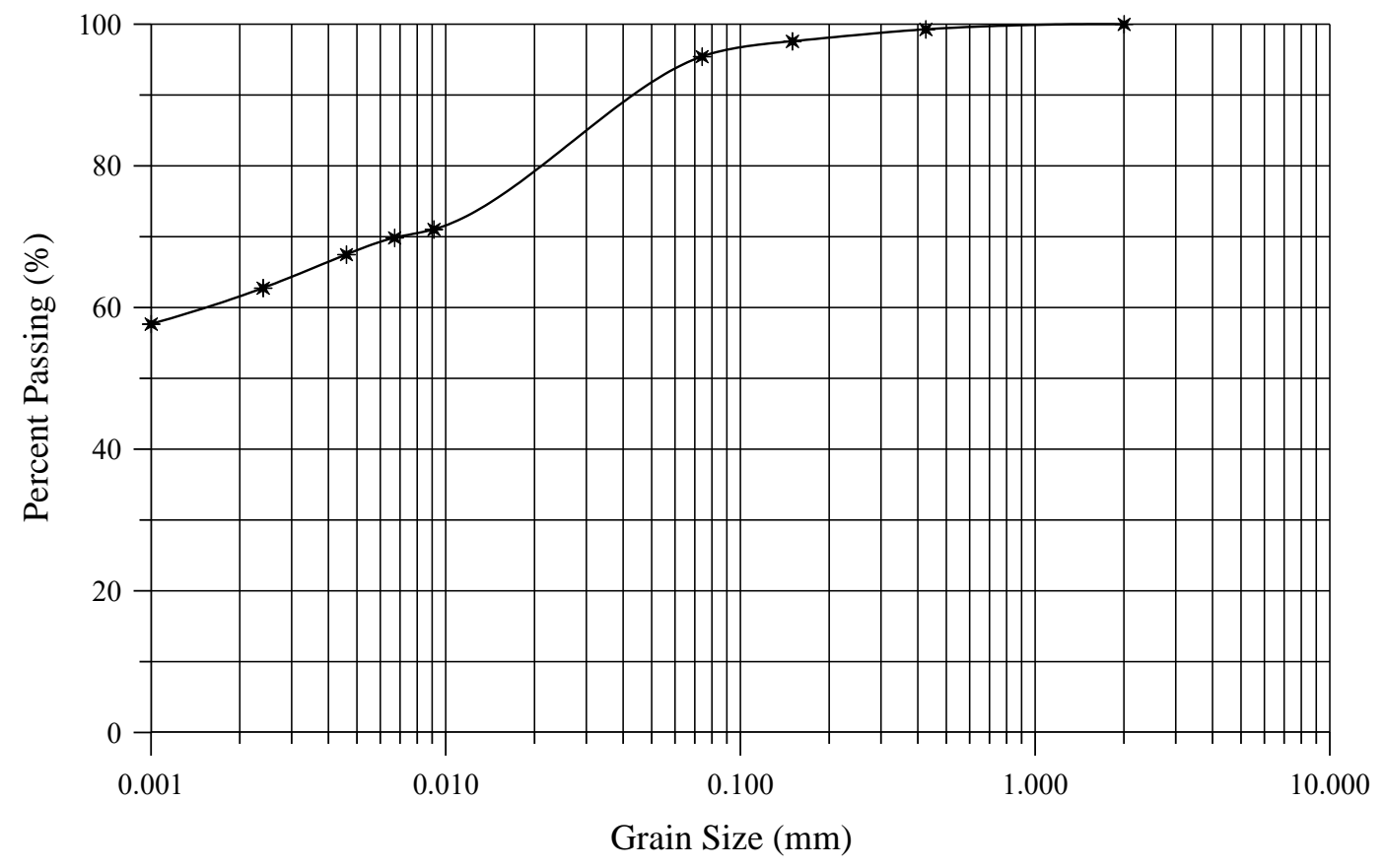

Figure 1 - Soil grain size distribution.

The natural soil is characterized by the following moisture and density properties: $\gamma=1840 \mathrm{~kg} / \mathrm{m}^{3}, \gamma_{\mathrm{d}}=1426$ $\mathrm{kg} / \mathrm{m}^{3}, \mathrm{~m}=29 \%, \mathrm{e}=0.855, \mathrm{n}=0.461$ and $\mathrm{S}=92.2 \%$. The soil is classified as Group A-7-5 according to the AASHTO classification system, while, according to the Unified Classification System, is classified as CH. The suitability of such soils as subgrades in pavement construction is judged as fair to poor.

Using the oedometer test, the swelling pressure of the soil has been found equal to $37.5 \mathrm{t} / \mathrm{m}^{2}$, while the free swell was equal to $28.1 \%$. The colloid content (\% percent smaller than $0.001 \mathrm{~mm}$ ) is $57.68 \%$, the linear shrinkage $17.91 \%$. Methylene blue tests performed on the soil yielded values of dye volume and apparent surface area equal to $19.5 \mathrm{~cm}^{3}$ and $251.55 \mathrm{~m}^{2} / \mathrm{gr}$ of soil, respectively.

In the present study, a fluvial aggregate material of sand size has been selected for the stabilization procedure of the swelling soil. Mixtures of the soil with the sand had been prepared in the laboratory on the basis of additive percentages, differing by $10 \%$ by soil weight from each other, starting from 
$10 \%$ and ending up to $100 \%$ (a mixture half soil and half sand). For each percentage of additive material, a set of three specimens was prepared.

The optimum moisture content for specimens formed using the various soil-sand ratios has been determined using the modified Proctor method according to AASHTO T180-15 specification. For the unconfined compression strength (UCS) test, cylindrical specimens with 2 in diameter and 5 in height $(5.08 \mathrm{~cm} \times 12.7 \mathrm{~cm})$ were used. The quantity of material for each sample was determined by the optimum moisture-maximum dry density relationship. For the preparation of strength specimens, the optimum moisture was used. The machine for the testing operated at a strain rate of $1.25 \mathrm{~mm} / \mathrm{min}$.

\section{Results and Discussion}

The liquid limit of both soil and soil-sand mixtures (passing the No. 40 sieve) was found using the Casagrande method. The liquid limit values decreased with the addition of sand. The same trend has been shown by the plasticity limit values, though the rate was less intense than that of LL. The decrease in plasticity index values is mainly due to the decrease of LL values. The variation in Atterberg limits with the addition of sand in various proportions is shown in Figure 2. Similar findings have been reported in other experimental works on soil stabilization with sand (Roy, 2003; Ravi Shankar et al., 2012).

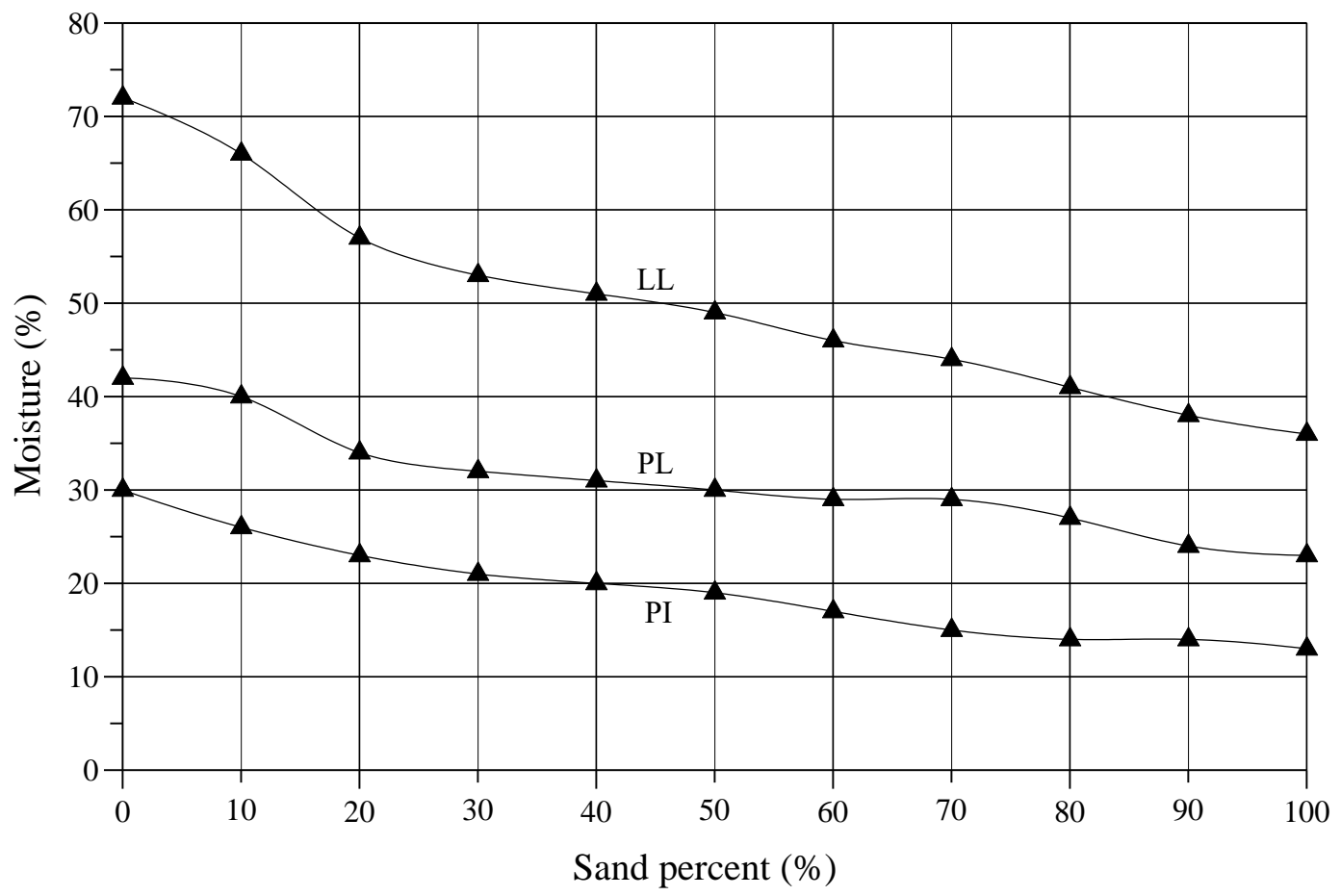

Figure 2 - Atterberg limits for soil mixtures with varying sand content.

Linear shrinkage of a soil specimen is the reduction of one of its dimensions, when the contained moisture being reduced from a given value reaches the maximum soil moisture and further reduction does not cause any soil volume change. The linear shrinkage was calculated using molds to produce semicircular specimens $140 \mathrm{~mm}$ long x $12.5 \mathrm{~mm}$ radius. Soil samples mixed with water up to the liquid limit value had been placed in the molds, according to BS 1377:Part 2:1990 specification.

The linear shrinkage of soil specimens with different sand contents was expressed as $\mathrm{LS}(\%)=(\Delta \mathrm{L} / \mathrm{L}) \times 100$ and is shown in Figure 3. 


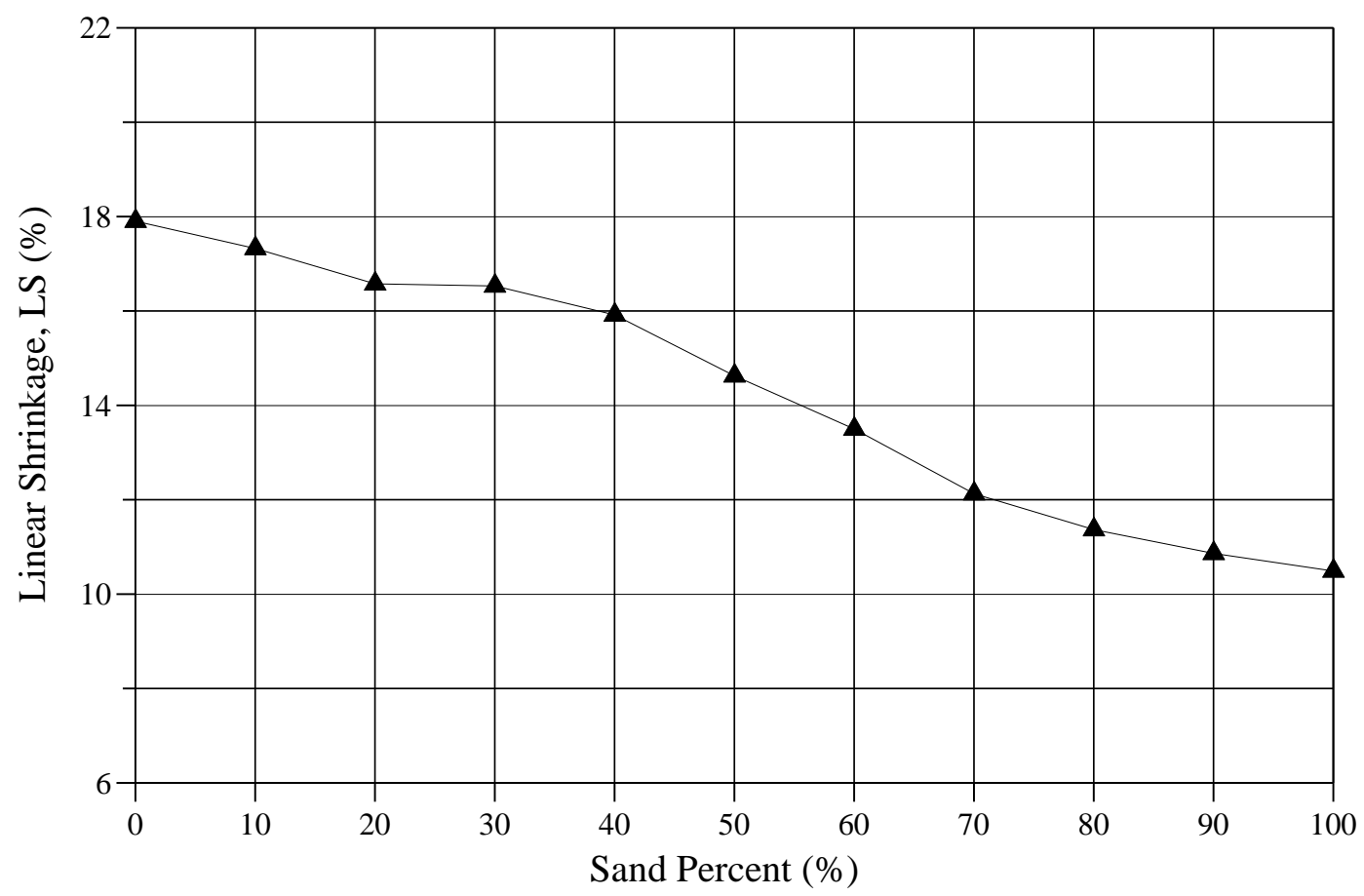

Figure 3 - Linear shrinkage for soil mixtures with varying sand content.

In order to find the dry density-moisture content relation with the standard Proctor compaction test, sand and soil samples passing the No. $4(4.75 \mathrm{~mm})$ sieve were used. The values of maximum dry density for the different soil-sand mixtures are presented in Figure 4. A continuous increase of MDD has been noted mainly because of the higher specific weight of the admixture material.

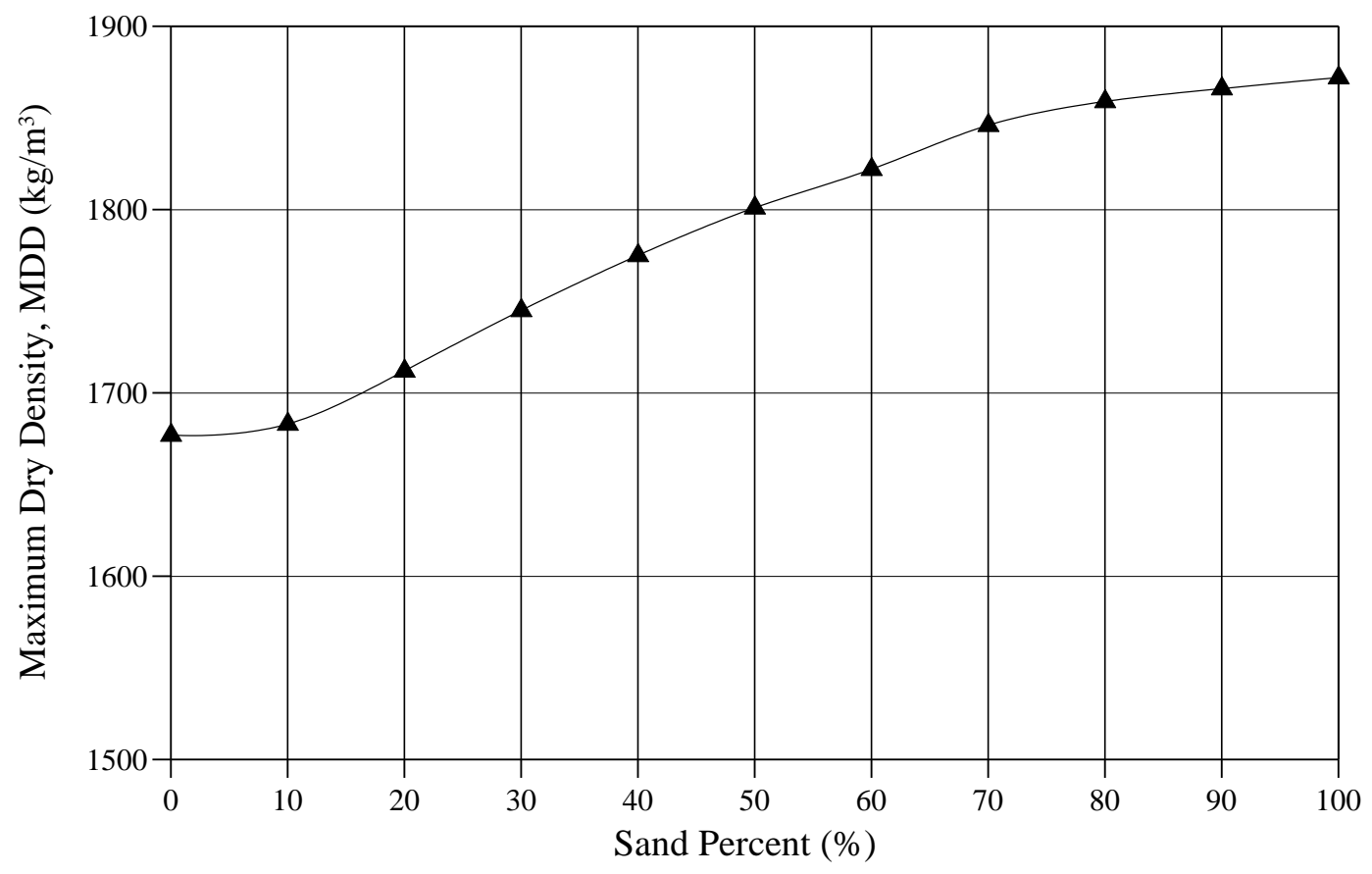

Figure 4 - Maximum dry density for soil mixtures with varying sand content. 
The values of optimum moisture content followed a reverse trend ranging from $21 \%$ for the natural soil up to $13.5 \%$ for the ratio 1:1 soil to sand, as it is shown in Figure 5.

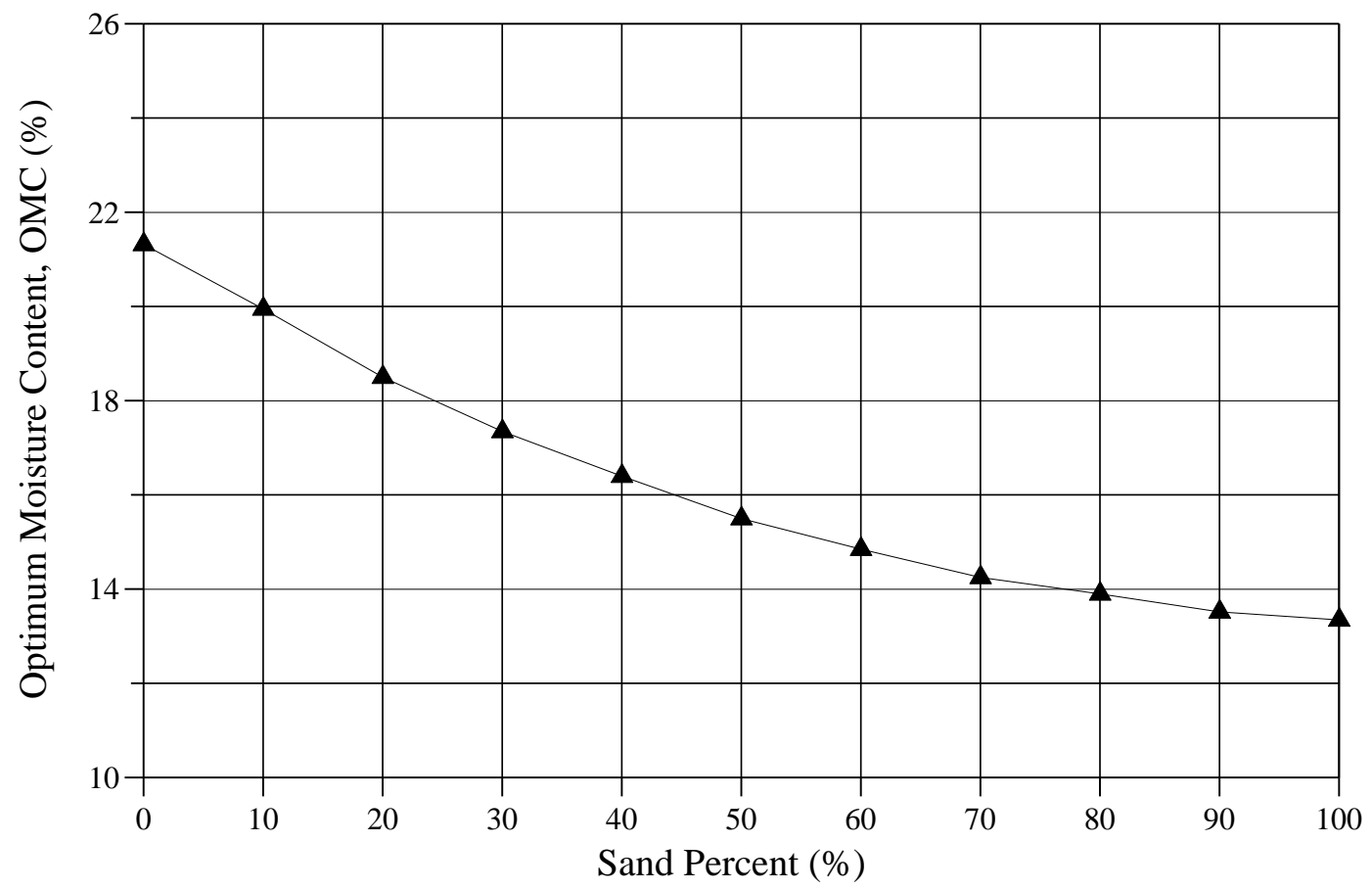

Figure 5 - Optimum moisture content for soil-sand mixtures.

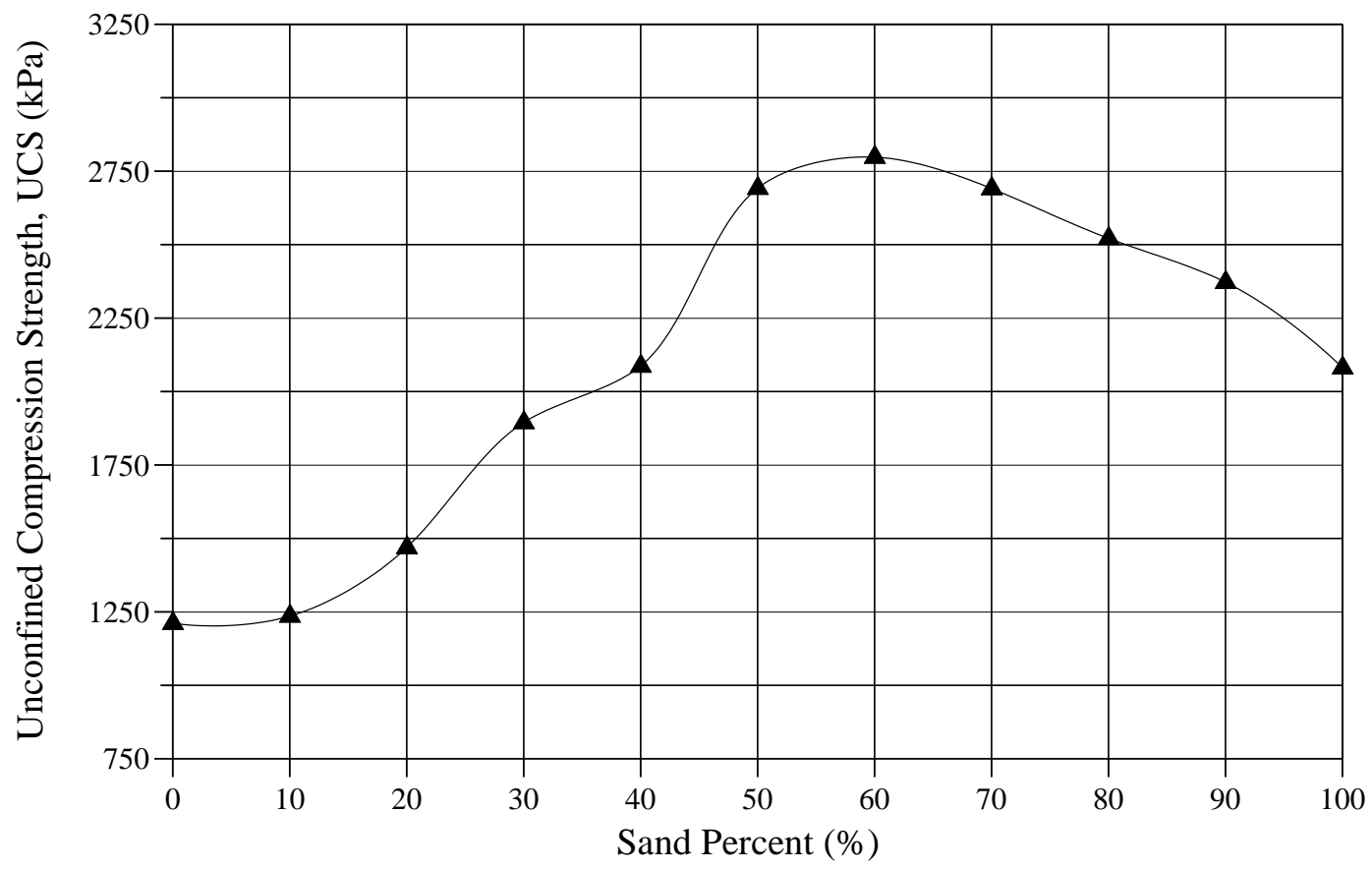

Figure 6 - Unconfined compression strength for soil mixtures with varying sand content.

The unconfined compression strength has increased for each sand addition increment up to $60 \%$ sand (from 1211 to 2798) and then linearly decreased for all other percentages (Figure 6). The 
decrease in strength values could be attributed to less cohesion between the particles in the mixture. It can be suggested that this proportion is an optimum for soil stabilization with sand.

In general, the compaction characteristics have been enhanced (increased maximum dry density and decreased optimum moisture content) with the addition of sand as the moisture-density curves have been shifted left and upper. This fact leads to the conclusion that the demand for water in order to achieve the desired field density values is lower. On the other hand, the strength gain reached the $131 \%$ with the addition of sand $60 \%$ by soil weight.

\section{Conclusions}

Since problematic soils are a worldwide problem, there is an increasing demand for techniques to improve their behaviour. Countries like Greece with their economies in crisis (low per capita income) or having low cement and lime production, can use the stabilization with sand technique in order to enhance soils to be used as pavement subgrades.

Based on the experimental results on clayey soil stabilized with sand, it could be concluded that:

- The Atterberg limits changed in a decreasing mode with the sand admixtures in ascending percentages. The liquid limit values initially indicated a decrease with the addition of sand. Further adding increased sand contents, the observed reduction in LL was small. The plastic limit showed slight alteration (reduction) with the increase of sand contents. The lower Pi values could be mainly attributed to the decrease of LL values.

- Linear shrinkage was decreased by $42 \%$ with stabilization. This finding can be interpreted as an indication that the soil can be used as a subgrade material for construction of flexible pavements in rural roads with low traffic volume.

- Referring to strength characteristics, the values of UCS tend to increase until a peak strength value had been reached with $60 \%$ sand by weight of soil.

\section{References}

Ameta, N.K., Purohit, D.G.M. and Wayal, A.S., 2007. Characteristics, problems and remedies of expansive soils of Rajasthan, India, Journal of Geotechnical Engineering, EJGE, J.N.V. University, Jodhpur, 7 pp.

Bengraa, L., Hachichi, A., Bourokba, S.A. and Benaissa, A., 2005. Étude de la stabilisation des argiles gonflantes par ajout de sable de carrière, Université du Tlemcen, Tlemcen, 101-112.

Bhatta, N., 2008. Engineering properties of pond ash and pond ash sand mixtures, Indian Highways, 36(7), 49-59.

Chavali, R.V.P. and Sharma, R.K., 2014. Influence of sand and fly ash on clayey soil stabilization. IOSR Journal of Mechanical and Civil Engineering (IOSR-JMCE) International Conference on Advances in Engineering \& Technology - 2014 (ICAET-2014), 36-40.

Gkasios, E. and Christodoulias, I., 2000. Investigation on the damages of the National Route near Thebes $(\mathrm{km} 70+000-90+000)$ due to expansive soils, 1-11. http://documents.scribd.com.s3.amazonaws.com/docs/1xfkew02gw2oah6t.pdf

Jjuuko, S., Kalumba, D. and Bagampadde, U., 2011. The use of locally available sand in stabilization of Ugandan clayey soils: Case study of clayey soil from Busega area, Uganda Institution of Professional Engineers $16^{\text {th }}$ National Technology Conference (NTC 2011), Umaru.

Kaoua, F., Derriche, Z. and Laradi, N., 1994. Contribution à l'étude de la stabilisation des sols gonflants par ajout de sable, Algérie Equipement: Revue Technique de l'Ecole National des Travaux Publiques, 15, 12-15.

Khemissa, M., Mahamedi, A. and Mekki, L., 2015. Problematic soil mechanics in the Algerian arid a nd semi-arid regions: Case of M'sila expansive clays, J. Appl. Eng. Sci. Technol., 1(2), 37-41. 
Lamara, M., Gueddouda, M.K. and Benabed, B., 2006. Stabilisation physico-chimique des argiles gonflantes (sable de dunes+sel), Revue Française de Géotechnique, 115, 25-35.

Lamara, M., Gueddouda, M.K., Benaissa, A. and Hachichi, A., 2005. Stabilisation des sols gonflants par ajout de sable de dune, Université du Tlemcen, Tlemcen, 129-139.

Louafi, B. and Bahar, R., 2012. SAND: An additive for stabilization of swelling clay soils, Int. J. Geosci., 3, 719-725.

Louafi, B. and Bahar, R., 2011. Étude en laboratoire de l'effet de l'apport d'un matériau inerte sur les caractéristiques de gonflement d'une marne argileuse, $10^{\text {th }}$ Edition of International Congress of Mechanics, École Nationale des Sciences Appliqués, Oujda, 293-295.

Madu, R.M., 1975. Sand-laterite mixtures for road construction (A laboratory investigation), Nigerian Journal of Technology, 1(1), 28-37.

Papakyriakopoulos, P., Koudoumakis, P. and Xidakis, G., 2006. Geotechnical problems in provincial road network of N. Evros prefecture, Proceedings $5^{\text {th }}$ Panhellenic Geotechnical and Geoenvironmental Conference, 44-52.

Ravi Shankar, A.U., Chandrasekhar, A. and Prakash Bhat H., 2012. Experimental investigations on lithomargic clay stabilized with sand and coir, Indian Highways, 40(2), 21-31.

Roy, T.K., 2013. Influence of sand on strength characteristics of cohesive soil for using as subgrade of road, Procedia - Social and Behavioral Sciences, 104, 218-224.

Sharma, R.K. and Gupta, C., 2013. Influence of waste materials on geotechnical characteristics of expansive soil, International Journal of Engineering Research \& Technology (IJERT), 2(10), 2536-2542.

Sharma, R.K., Kumar, V., Sharma, N. and Rathore, A., 2012. Compaction and subgrade characteristics of clay mixed with beas sand, rice husk ash and waste plastic fibre, Indian Highways, 40(8), 29-36.

Singh, B, Kumar, A. and Sharma, R.K., 2014. Effect of waste materials on strength characteristics of local clay, International Journal of Civil Engineering Research, 5(1), 61-68. 